\title{
Pre-Harvest Forecasting of Rice Yield for Effective Crop Planning Decision in Surat District of South Gujarat, India
}

\author{
K. B. Banakara ${ }^{*}$, Y. A. Garde ${ }^{2}$, R. R. Pisal ${ }^{3}$ and B. K. Bhatt ${ }^{4}$ \\ ${ }^{1}$ Department of Agricultural Statistics, Navsari Agricultural University, Navsari, \\ Gujarat - 396 450, India \\ ${ }^{2}$ Department of Agricultural Statistics, College of Agriculture, Navsari Agricultural \\ University, Waghai, Dang, Gujarat - 394730, India \\ ${ }^{3}$ Department of Agronomy, College of Agriculture, Navsari Agricultural University, Waghai, \\ Dang, Gujarat - 394730, India \\ ${ }^{4}$ Department of Agricultural Statistics, ASPEE College of Horticulture and Forestry, Navsari \\ Agricultural University, Navsari, Gujarat - 396 450, India \\ *Corresponding author
}

A B S T R A C T

\begin{tabular}{|l|}
\hline Ke y w or d s \\
$\begin{array}{l}\text { Weather indices; MLR } \\
\text { techniques; Discriminant } \\
\text { function analysis; } \\
\text { Forecast }\end{array}$ \\
\hline Article Info \\
\hline $\begin{array}{l}\text { Accepted: } \\
\text { 22 May 2018 } \\
\text { Available Online: } \\
\text { 10 June 2018 }\end{array}$ \\
\hline
\end{tabular}

In the Gujarat State, rice occupies about 7 to 8 per cent of the gross cropped area and accounts for about 14.00 per cent of the total food grain production. Pre harvest forecast may provide useful information to agriculturalists, administration offices and merchants. In the current study statistical crop modeling was engaged to provide forecast in advance harvesting for taking timely pronouncements. In this paper Multiple Linear Regression (MLR) Technique and Discriminant function analysis were derived for estimating average rice production for the district of Surat in south Gujarat. The weather indices were developed using correlation coefficient as weight toweekly weather parameters for the years from 1975 to 2009 . The cross authentication of the developed forecast model were confirmed using data of the years 2010 to 2012. It was observed that value of Adj. $\mathrm{R}^{2}$ varied from 0.64 to 0.80 in different models. The study discovered that high value of Adj. $\mathrm{R}^{2}$ was obtained in the model and which indicated that it was appropriate forecast model than other models. Based on the outcomes in Surat district, MLR techniques found to be better than Discriminant function analysis for pre harvest forecasting of rice crop yield.

\section{Introduction}

Rice (Oryza sativa $\mathrm{L}$.) is regarded as a first cultivated crop of Asia. More than 90per cent of the world's rice is grown and consumed in Asia, where 60per cent of the world's population lives. Agriculture is the mainstay of Indian economy. Agriculture and allied sciences contributes nearly 22 percent of Gross Domestic Products (GDP) of India, while about 65-70 per cent of the population is dependent on agriculture for their livelihood. About 60 percent of sown area is dependent on rainfall as a main source of irrigation.India is an important rice growing countries in the world which has the largest area (44.8 million 
hectares) followed by China and Bangladesh. In respect of production, India ranks second with 154.6 million tonnes of paddy (103.6 million tones, milled basis) next to China (206.4 million tonnes of paddy, 144.4million tones on milled basis), (FAO, 2015). In the Gujarat state, rice is grown on an average about 6.50 to 7.25 lakh hectares of land comprising nearly 55 to 60 per cent of low land (transplanted) and 40 to 45 per cent of upland (drilled) rice. The prediction of weather conditions can have significant impacts on various sectors of society in different parts of the country. Forecasts are used by the government \&industry to protect life and property. It helps in improve the efficiency of operations by planning. The weather and climatic information plays a major role before and during the cropping season and if provided in advance it can be helpful in stirring the farmer to form and use their own resources in order to gather the benefits. The advance knowledge of weather parameters in a particular region is advantageous in effective planning.

The crop weather relationship has been studied by Fisher (1924) and Hendricks and Scholl (1943) have done pioneering work at Indian Agricultural Statistic Research Institute, New Delhi. They developed models which required small number of parameters to be estimated while taking care of distribution pattern of weather over the crop season. Agrawal et al., (1980) and Jain et al., (1980) modified this model by expressing effects of changes in weather parameters on yield in the particular week as second degree polynomial in respective correlation coefficients between yield and weather parameters. This model was further modified (Agrawal et al., 1986, 2011) by explaining the effects of changes in weather parameters on yield in particular week using linear function.Garde et al., (2012) studied correlation and multiple regression analysis for pre harvest forecasting of rice yield in the Pantnagar. The study proposed that modified model with incorporating technical and statistical indicators were effectively used for early pre-harvest forecasting of crop. Dhekale et al., (2014) developed the pre harvest forecast models using multiple linear regression (MLR) technique and found that the $18^{\text {th }}$ SMW forecast model accounts for 89 per cent of variation in yield with RMSE 107. Sisodia et al., (2014) applied discriminant function analysis on meteorological parameters for developing suitable statistical models for forecasting rice yield in Faizabad, U.P. Garde et al., (2015) studied different approaches on pre harvest forecasting of wheat yield using MLR and discriminant function techniques in Varanasi district and found MLR technique more suitable than discriminant function techniques. Kumar et al., (2016) studied crop yield forecasting of paddy and sugarcane through modified Hendrick and Scholl technique for south Gujarat using weather parameters. Pisal et al., (2017) determined the long term changes in rainfall using MannKendall rank statistics and linear trend analysis.

In the current situation of India faces increasing population and industrial development which are adversely distressing the crop yield in India.Keeping in mind early crop yield forecast will help farmer to formulate the cropping pattern, agricultural practices which will results in to the increase yield of the farmers. Therefore main objective of the present study was to develop a simple approach for forecasting the rice yield before harvesting with help of weather parameters.

\section{Materials and Methods}

The present study was carried out in the Surat, district of South Gujarat. Surat is a one of the leading districts with respect to area, production and productivity of kharif rice. 
Considering the specific objectives of the study, kharif rice yield data were collected from the Directorate of Economics and Statistics, Government of Gujarat, Gandhinagar, Gujarat from 1975 to 2012. The distribution of crop yield over the year is shown in Figure 1. The study utilised weekly weather data which were collected from the Indian Meteorological Department (IMD), Pune for period of thirty four years (19752012). The maximum temperature (X1), minimum temperature (X2), relative humidity (X3), wind speed (X4), and total rain fall (X5) considered for studying the effect on kharif rice grain yield. The weekly weather data related to Kharif crop season starting from a first fortnight before sowing to last of reproductive stage were utilized for the development of statistical models. Therefore for the each year weather data, from May-June $\left(22^{\text {nd }}\right.$ standard meteorological week, SMW) to October $\left(41^{\text {st }}\right.$ standard meteorological week, SMW) were utilized for kharif crop. The details of the yearly average of weather parameters for kharif season is given in Table1

\section{Statistical methodology}

\section{Multiple Linear Regression models (MLR)}

The MLR models were developed using weather indices (Agrawal et al., 1986, 2011), in this method, weekly data on weather variables of 20 weeks have been utilized for constructing weather indices (weighted \& unweighted along with their interactions). The forms of indices are given as below:

$$
Z_{i, j}=\sum_{w=1}^{m} r_{i w}^{j} X_{i w} \quad Z_{i, i^{\prime}, j}=\sum_{w=1}^{m} r_{i i^{\prime} w}^{j} X_{i^{\prime} w}
$$

Where,

$j=0,1$ (where, ' 0 ' represents un-weighted indices and ' 1 ' represents weighted indices) $m=$ Week up to forecast $\left(m=20^{t h}\right)$

$w=$ week number $(1,2, \ldots ., m)$

$r_{i w}=$ Correlation coefficient between adjusted crop yield and $i^{\text {th }}$ weather variable in $w^{\text {th }}$ week

$r_{i i{ }^{\prime} w}=$ Correlation coefficient between adjusted crop yield and the product of $i$ and $i^{\text {,h }}$ weather variable in $w^{\text {th }}$ week

$X_{i w}$ and $X_{i{ }^{\prime} w}$ are the $i$ and $i^{\text {th }}$ weather variable in $w^{\text {th }}$ week respectively

The pre-harvest forecast models were obtained by applying the MLR techniques by taking predictors as appropriate un-weighted and weighted weather indices. Stepwise regression analysis was used for selecting significant variables (Draper and Smith 1981; Gomez and Gomez 1984). The regression model was as follows:

\section{Model-1}

$Y=A_{0}+\sum_{i=1}^{p} \sum_{j=0}^{1} a_{i, j} Z_{i, j}+\sum_{i \neq i^{\prime}=1}^{p} \sum_{j=0}^{1} a_{i . i^{\prime} \cdot j} Z_{i, i^{\prime}, j}+c T+e$

Where,

$Z_{i, j}$ and $Z_{i, i^{\prime}, j}$ are the weather indices

$i, i^{\prime}=1,2, \ldots \mathrm{p}$

$p=$ Number of weather variables under study

$Y=$ District total crop yield (q/ha)

$T=$ Year number (trend parameter)

$A_{0}$ is the intercept

$a i j, a i i^{\prime} j, c$ are the regression coefficient

$e$ is error term normally distributed with mean zero and constant variance 


\section{Discriminant function analysis}

Discriminant function analysis is a multivariate technique discussed by Anderson (1984), Hair et al., (1995), Johnson and Wichern (2006) etc. Discriminant analysis is an appropriate statistical technique when the dependent parameter is categorical and the independent parameters are metric. It involves deriving a variate, a linear combination of two or more independent parameters that will discriminate best between prior defined groups. In present study crop years has been divided into three groups namely congenial, normal and adverse on the basis of crop yield adjusted for trend effect. Data on weather parameters in these three groups were used to develop linear or quadratic discriminant functions and the discriminant scores were obtained for each year. These scores were used along with year as regressors in developing the forecast models (Garde et al., 2015).

\section{Method-1}

In this method the model was developed by considering five weighted weather indices $\left.Z_{i, j}=\sum_{w=1}^{m} r_{i w}^{j} X_{i w}\right]$. The discriminant function analysis was carried out and two discriminant score have been obtained. For developing quantitative forecast, these two sets of discriminant scores along with trend parameter (year) were used as the regressors and crop yield as the regress and. The form of the developed model is as follows:

\section{Model-2}

$Y=\beta_{0}+\beta_{1} d s_{1}+\beta_{2} d s_{2}+\beta_{3} T+\varepsilon$

Where,

$Y$ is un-trended crop yield, $\beta_{i}$ 's $(i=0,1,2,3)$ are model parameter, $T$ is the trend parameter

$d s_{1}$ and $d s_{2}$ are discriminant scores and $\varepsilon$ is error term assumed to follow NID $\sim\left(0, \sigma^{2}\right)$.

\section{Method-2}

In this method, 5 weighted and 5 un-weighted weather indices of five weather parameters were used as discriminating parameters in the discriminant function analysis. Two sets of scores were obtained $\left(d s_{1}\right.$ and $\left.d s_{2}\right)$.

The forecasting model was fitted taking the yield as the regressand and the two sets of scores along with trend $T$ as the regessors. The form of model considered is as follows:

\section{Model-3}

$Y=\beta_{0}+\beta_{1} d s_{1}+\beta_{2} d s_{2}+\beta_{3} T+\varepsilon$

Where, $Y$ is un-trended crop yield,

$\beta_{i}$ 's $(i=0,1,2,3)$ are model parameter, $T$ is the trend parameter

$d s_{1}$ and $d s_{2}$ are discriminant scores and $\varepsilon$ is error term assumed to follow NID $\sim\left(0, \sigma^{2}\right)$.

\section{Method-3}

The method utilized all thirty developed weather indices (weighted and un-weighted including interaction indices) as discriminating parameters in discriminant analysis. The two sets of discriminant scores were obtained ( $d s_{1}$ and $\left.d s_{2}\right)$ and used as the regessors along with trend variable $T$. The form of model considered is as follows:

\section{Model-4}

$Y=\beta_{0}+\beta_{1} d s_{1}+\beta_{2} d s_{2}+\beta_{3} T+\varepsilon$ 
Where,

$Y$ is un-trended crop yield,

$\beta_{i}$ 's $(i=0,1,2,3)$ are model parameter, $T$ is the trend parameter

$d s_{1}$ and $d s_{2}$ are discriminant scores and $\varepsilon$ is error term assumed to follow NID $\sim\left(0, \sigma^{2}\right)$.

\section{Method-4}

In this method, discriminant function analysis was carried out using the average of unweighted and weighted weather indices which were obtained for the first weather parameter i.e. maximum temperature, $\left(X_{1}\right)$. The discriminant function analysis were carried out and got two sets of discriminant scores. Next these two sets of discriminant scores and averages of un-weighted \&weighted indices of the second weather parameter i.e. minimum temperature $\left(X_{2}\right)$ were used as discriminating parameters. The two sets of discriminant scores were obtained through discriminant function analysis. The procedure continues up to fifth weather parameter i.e. total rainfall $\left(X_{5}\right)$. The forecasting model was fitted taking the yield as the regress and last two sets of scores ( $d s_{1}$ and $d s_{2}$ ) along with trend $T$ as the regessors. The form of model considered is as follows:

\section{Model-5}

$$
Y=\beta_{0}+\beta_{1} d s_{1}+\beta_{2} d s_{2}+\beta_{3} T+\varepsilon
$$

Where,

$Y$ is un-trended crop yield,

$\beta_{i}$ 's $(i=0,1,2,3)$ are model parameter, $T$ is the trend parameter

$d s_{1}$ and $d s_{2}$ are discriminant scores and $\varepsilon$ is error term assumedto follow NID $\sim\left(0, \sigma^{2}\right)$.
This model utilizes the complete data over 20 weeks and also considers relative importance of weather parameters in different weeks.

\section{Comparison and validation of models}

The comparisons and validation of models were done using following approaches

\section{Forecast error (\%)}

The validation of the model using observed yield $\left(\mathrm{O}_{\mathrm{i}}\right)$ and forecasted yield $\left(\mathrm{E}_{\mathrm{i}}\right)$ was computed using below formula,

Forecast Error $=\left[\frac{O_{i}-E_{i}}{O_{i}}\right] \times 100$

Coefficient of multiple determination (Adjusted $\mathbf{R}^{2}$ )

The best fitted model among developed models were decided based on highest value of Adjusted $R^{2}$

$$
R_{a d j}^{2}=1-\frac{S S_{r e s} /(n-p)}{S S_{t} /(n-1)}
$$

Where,

$s s_{r e s} d(n-p)$ is the residual mean square

$s s_{t} /(n-1)$ is the total mean sum of square.

\section{Root mean square error (RMSE)}

The cross validation of the model were done using RMSE, for the year 2010 to 2012 using observed yield $\left(\mathrm{O}_{\mathrm{i}}\right)$ and forecasted yield $\left(\mathrm{E}_{\mathrm{i}}\right)$ was computed using below formula,

$R M S E=\left[\frac{1}{n} \sum_{i=1}^{n}\left(O_{i}-E_{i}\right)^{2}\right]^{1 / 2}$ 


\section{Results and Discussion}

\section{Association between Rice Yield and Weather Parameters}

The associations between rice yield and week wise weather parameters were studied by using Karl Pearson correlation coefficient (Table 2). The main aim was to know strength between rice yield and weekly weather parameters.

The Positive significant correlation coefficient was observed between rice yields( $(\mathrm{Y})$ and some of the weekly weather parameters. It was found that 70 per cent weeks were positively significant correlation coefficient between yield and minimum temperature. The relative humidity $\left(37^{\text {th }}\right.$ SMW) and rain fall $\left(36^{\text {th }}\right.$ SMW) also found positively significant. The negatively significant correlation coefficient was observed between rice yield and maximum temperature $\left(39^{\text {th }}\right.$ SMW $)$. The remaining weeks found non-significant correlation coefficient between rice yields $(\mathrm{Y})$ and the weekly weather parameters. The value of ' $r$ ' varies from -0.352 to 0.667 indicating that individual character does not explain more than 67 per cent variation in the yield. This suggests that simple regression using single weather parameter is not adequate to forecast the yield. It is necessary to utilize all weather parameters simultaneously. It is done by constructing un-weighted indices and weighted indices.

\section{Statistical models}

The models were developed for the SMW no from 32 to 37, keeping in the mind forecast of crop yield at least one month before harvest

\section{Multiple Linear Regression models (MLR)}

Based on strategies followed in model 1, the obtained forecast model equations are given in
Table 3. The Table 3 observed that the values of adjusted $\mathrm{R}^{2}$ for different models were varied from 66.5 per cent (model $\mathrm{A}_{1}$ ) to 80.2 per cent (model $\mathrm{A}_{6}$ ). Based on highest value of adjusted $\mathrm{R}^{2}$ model $\mathrm{A}_{6}$ was selected as a best model among developed six models which found to be appropriate in the 37 SMW i.e. five weeks before the harvest of crop.

The model showed 80.2 per cent variation accounted due to weather indices $Z_{21}, Z_{131}$ and $Z_{451}$ and trend variable $T$.

\section{Discriminant Function Analysis}

The different methods were adopted using discriminant function analysis and detailed of the developed models below:

As discussed in method 1, the pre harvest rice yield forecast model 2equations are given in Table 4 . The Table 4 observed that the values of adjusted $\mathrm{R}^{2}$ for different models were varied from 64.1 per cent (model $\mathrm{B}_{1}$ ) to 66.5 per cent (model $\mathrm{B}_{6}$ ). Based on highest value of adjusted $\mathrm{R}^{2}$ model $\mathrm{B}_{6}$ was selected as a best model among developed six models which found to be appropriate in the 37 SMW i.e. five weeks before the harvest of crop. The model showed 66.5 per cent variation accounted due to $d s_{1}$ and trend variable $T$.

As discussed in method 2, the pre harvest rice yield forecast model 3equations are given in Table 5. The Table 5 observed that the values of adjusted $\mathrm{R}^{2}$ for different models were varied from 64.1 per cent (model $\mathrm{C}_{1}$ ) to 66.5 per cent (model $\mathrm{C}_{6}$ ).

Based on highest value of adjusted R2model C6 was selected as a best model among developed six models which found to be appropriate in the 37 SMW i.e. five weeks before the harvest of crop. The model showed 66.5 per cent variation accounted due tods 1 and trend variable $\mathrm{T}$. 
Table.1 The average of weather variables for cropping season of Surat district of south Gujarat

\begin{tabular}{|c|c|c|c|c|c|}
\hline Year & $\begin{array}{c}\text { Max. } \\
\text { Temp. }\end{array}$ & $\begin{array}{c}\text { Min. } \\
\text { Temp. }\end{array}$ & $\begin{array}{c}\text { Relative } \\
\text { Humidity }\end{array}$ & $\begin{array}{c}\text { Wind } \\
\text { Speed }\end{array}$ & $\begin{array}{c}\text { Rain } \\
\text { Fall }\end{array}$ \\
\hline 1975 & 32.1 & 25.6 & 87.8 & 10.2 & 78.6 \\
\hline 1976 & 32.1 & 25.3 & 85.5 & 8.8 & 112.5 \\
\hline 1977 & 32.5 & 24.6 & 84.6 & 8.7 & 56.2 \\
\hline 1978 & 32.3 & 24.1 & 82.4 & 0.0 & 58.3 \\
\hline 1979 & 32.9 & 23.4 & 82.5 & 8.9 & 66.5 \\
\hline 1980 & 32.5 & 25.3 & 83.0 & 10.2 & 50.8 \\
\hline 1981 & 32.6 & 25.4 & 82.8 & 10.4 & 58.4 \\
\hline 1982 & 32.9 & 26 & 82.4 & 10.2 & 56.4 \\
\hline 1983 & 32.4 & 25.4 & 87.5 & 0.2 & 96.2 \\
\hline 1984 & 31.9 & 25 & 83.7 & 0.2 & 43.1 \\
\hline 1985 & 32.6 & 25.4 & 81.2 & 0.4 & 15.7 \\
\hline 1986 & 32.3 & 25.7 & 80.2 & 0.0 & 49.5 \\
\hline 1987 & 34.0 & 26.0 & 75.6 & 0.0 & 25.4 \\
\hline 1988 & 32.5 & 24.6 & 84.9 & 0.0 & 113.9 \\
\hline 1989 & 32.5 & 26.1 & 78.7 & 0.0 & 16.0 \\
\hline 1990 & 31.7 & 26.1 & 84.2 & 0.0 & 43.2 \\
\hline 1991 & 32.6 & 25.7 & 79.9 & 0.4 & 32.1 \\
\hline 1992 & 31.7 & 26.1 & 84.1 & 0.0 & 05.3 \\
\hline 1995 & 33.8 & 26.4 & 77.3 & 0.1 & 30.3 \\
\hline 1997 & 32.5 & 25.9 & 79.8 & 0.0 & 47.7 \\
\hline 1998 & 33.9 & 26.7 & 79.9 & 0.0 & 75.9 \\
\hline 1999 & 32.5 & 26.3 & 84.9 & 0 & 46.8 \\
\hline 2000 & 32.4 & 26.4 & 83.3 & 8 & 36.1 \\
\hline 2001 & 31.6 & 26 & 86.1 & 7.1 & 53.3 \\
\hline 2002 & 31.9 & 25.8 & 84.5 & 5.4 & 52.3 \\
\hline 2004 & 31.8 & 25.8 & 84.8 & 3.9 & 83.9 \\
\hline 2005 & 32 & 26 & 83.7 & 5.6 & 100 \\
\hline 2006 & 31.7 & 26.2 & 85.2 & 3.6 & 72.3 \\
\hline 2007 & 32.2 & 26 & 86.7 & 4.3 & 82 \\
\hline 2008 & 31.5 & 25.8 & 87.2 & 5.8 & 64.1 \\
\hline 2009 & 32.5 & 26.5 & 84.4 & 6.5 & 66.3 \\
\hline 2010 & 32.3 & 26.3 & 87.4 & 5 & 75.8 \\
\hline 2011 & 31.9 & 26.5 & 85.2 & 7.5 & 60.8 \\
\hline 2012 & 32 & 26.7 & 86.2 & 8.7 & 41.8 \\
\hline & & & & & \\
\hline
\end{tabular}


Table.2 Week wise correlation coefficient between rice yield and weekly weather parameters

\begin{tabular}{|c|c|c|c|c|c|}
\hline \multirow[t]{2}{*}{$\begin{array}{l}\text { SMW } \\
\text { no. }\end{array}$} & \multicolumn{5}{|c|}{$\begin{array}{l}\text { Correlation coefficient between rice yield }(Y) \text { and weekly weather } \\
\text { parameters }\left(X_{i}\right)\end{array}$} \\
\hline & Max. temp. & Min. temp. & Rel. Humidity & Wind Speed & Rainfall \\
\hline$\overline{w_{i}}$ & $X_{1}$ & $X_{2}$ & $X_{3}$ & $X_{4}$ & $X_{5}$ \\
\hline 22 & -0.186 & $0.386^{*}$ & 0.167 & -0.125 & 0.149 \\
\hline 23 & 0.113 & $0.486^{*}$ & -0.145 & -0.121 & -0.312 \\
\hline 24 & -0.075 & 0.329 & 0.081 & -0.16 & 0.003 \\
\hline 25 & 0.191 & $0.481 *$ & -0.141 & 0.029 & -0.332 \\
\hline 26 & 0.137 & 0.42 & 0.024 & -0.061 & -0.089 \\
\hline 27 & 0.032 & 0.29 & 0.126 & -0.203 & 0.215 \\
\hline 28 & -0.001 & $0.382 *$ & 0.018 & -0.119 & -0.189 \\
\hline 29 & -0.13 & 0.321 & 0.112 & -0.172 & 0.196 \\
\hline 30 & -0.102 & $0.351 *$ & 0.179 & -0.026 & -0.034 \\
\hline 31 & 0.026 & $0.469 *$ & 0.066 & -0.019 & -0.071 \\
\hline 32 & -0.004 & $0.525^{*}$ & 0.008 & -0.01 & -0.091 \\
\hline 33 & 0.105 & $0.690 *$ & 0.049 & -0.029 & 0.167 \\
\hline 34 & 0.038 & $0.667 *$ & 0.052 & -0.182 & 0.189 \\
\hline 35 & 0.033 & $0.602 *$ & 0.228 & -0.215 & 0.179 \\
\hline 36 & -0.127 & $0.68 *$ & 0.235 & -0.041 & $0.424^{*}$ \\
\hline 37 & -0.186 & $0.593^{*}$ & $0.377^{*}$ & -0.127 & 0.131 \\
\hline 38 & -0.153 & $0.605^{*}$ & 0.256 & -0.079 & 0.003 \\
\hline 39 & $-0.352 *$ & $0.412 *$ & 0.179 & -0.141 & 0.132 \\
\hline 40 & -0.222 & 0.274 & 0.161 & -0.089 & -0.094 \\
\hline 41 & -0.263 & 0.19 & 0.295 & -0.148 & 0.221 \\
\hline
\end{tabular}

Table.3 Pre harvest rice yield forecast model 1 equations

\begin{tabular}{|c|c|c|c|}
\hline Model1 & $\begin{array}{l}\text { SMW } \\
\text { No. }\end{array}$ & Model Equations & Adj. $\mathbf{R}^{2}$ \\
\hline $\mathbf{A}_{1}$ & 32 & $Y=-216.759+25.520 T+2.423 Z_{121}$ & 0.665 \\
\hline$\overline{\mathbf{A}_{2}}$ & 33 & $Y=-1258.536+27.521 T+1.828 Z_{121}+1.195 Z_{131}$ & 0.715 \\
\hline$\overline{\mathbf{A}_{3}}$ & 34 & $Y=-1659.396+27.460 T+1.186 Z_{131}+1.758 Z_{121}$ & 0.716 \\
\hline$\overline{\mathbf{A}_{4}}$ & 35 & $Y=-1887.861+21.368 T+261.445 Z_{21}+8.956 Z_{20}$ & 0.738 \\
\hline$\overline{\mathbf{A}_{5}}$ & 36 & $Y=-859.329+29.360 T+157.551 Z_{21}+1.075 Z_{131}$ & 0.747 \\
\hline$\overline{\mathbf{A}_{6}}$ & 37 & $\begin{aligned} Y=- & 1627.208+27.479 T+97.952 Z_{21}+1.009 Z_{131}+ \\
& 0.087 Z_{451}\end{aligned}$ & 0.802 \\
\hline
\end{tabular}


Table.4 Pre harvest rice yield forecast model 2 equations

\begin{tabular}{|l|l|l|l|}
\hline Model 2 & $\begin{array}{l}\text { SMW } \\
\text { No. }\end{array}$ & Model Equations & Adj. $\mathbf{R}^{2}$ \\
\hline$B_{1}$ & 32 & $Y=1219.833+30.428 T+86.697 d s_{1}$ & 0.641 \\
\hline$B_{2}$ & 33 & $Y=1268.057+27.414 T+87.349 d s_{1}$ & 0.651 \\
\hline$B_{3}$ & 34 & $Y=1269.126+27.347 T+87.316 d s_{1}$ & 0.652 \\
\hline$B_{4}$ & 35 & $Y=1268.051+27.414 T+87.815 d s_{1}$ & 0.654 \\
\hline$B_{5}$ & 36 & $Y=1268.653+27.377 T+87.715 d s_{1}$ & 0.653 \\
\hline$B_{6}$ & 37 & $Y=1266.013+27.542 T+90.914 d s_{1}$ & 0.665 \\
\hline
\end{tabular}

Table.5 Pre harvest rice yield forecast model 3 equations

\begin{tabular}{|l|l|l|l|}
\hline Model 3 & SMW No. & Model Equations & Adj. $\mathbf{R}^{2}$ \\
\hline $\mathrm{C}_{1}$ & 32 & $Y=1219.833+30.428 T+86.697 d s_{1}$ & 0.641 \\
\hline $\mathrm{C}_{2}$ & 33 & $Y=1268.057+27.414 T+87.349 d s_{1}$ & 0.651 \\
\hline $\mathrm{C}_{3}$ & 34 & $Y=1269.126+27.347 T+87.316 d s_{1}$ & 0.652 \\
\hline $\mathrm{C}_{4}$ & 35 & $Y=1268.051+27.414 T+87.815 d s_{1}$ & 0.654 \\
\hline $\mathrm{C}_{5}$ & 36 & $Y=1268.653+27.377 T+87.715 d s_{1}$ & 0.653 \\
\hline $\mathrm{C}_{6}$ & 37 & $Y=1266.013+27.542 T+90.914 d s_{1}$ & 0.665 \\
\hline
\end{tabular}

Table.6 Pre harvest rice yield forecast model 4 equations

\begin{tabular}{|l|l|l|l|}
\hline Model 4 & SMW No. & Model Equations & Adj. $\mathbf{R}^{2}$ \\
\hline $\mathbf{D}_{1}$ & 32 & $Y=1219.833+30.428 T+86.697 d s_{1}$ & 0.641 \\
\hline $\mathbf{D}_{2}$ & 33 & $Y=1267.517+27.4484 T+87.824 d s_{1}$ & 0.653 \\
\hline $\mathbf{D}_{3}$ & 34 & $Y=1268.407+27.392 T+87.724 d s_{1}$ & 0.654 \\
\hline $\mathbf{D}_{4}$ & 35 & $Y=1267.234+27.465 T+88.265 d s_{1}$ & 0.655 \\
\hline $\mathbf{D}_{5}$ & 36 & $Y=1204.214+31.404 T+107.210 d s_{1}$ & 0.691 \\
\hline $\mathbf{D}_{6}$ & 37 & $Y=1265.762+27.557 T+90.634 d s_{1}$ & 0.665 \\
\hline
\end{tabular}


Table.7 Pre harvest rice yield forecast model 5 equations

\begin{tabular}{|l|l|l|l|}
\hline Model 5 & SMW No. & Model Equations & Adj. $\mathbf{R}^{2}$ \\
\hline $\mathrm{E}_{1}$ & 32 & $Y=1219.833+30.428 T+86.697 d s_{1}$ & 0.641 \\
\hline $\mathrm{E}_{2}$ & 33 & $Y=1268.057+27.414 T+87.349 d s_{1}$ & 0.651 \\
\hline $\mathrm{E}_{3}$ & 34 & $Y=1269.126+27.347 T+87.316 d s_{1}$ & 0.652 \\
\hline $\mathrm{E}_{4}$ & 35 & $Y=1268.051+27.414 T+87.815 d s_{1}$ & 0.654 \\
\hline $\mathrm{E}_{5}$ & 36 & $Y=1268.653+27.377 T+87.715 d s_{1}$ & 0.653 \\
\hline $\mathrm{E}_{6}$ & 37 & $Y=1266.013+27.542 T+90.914 d s_{1}$ & 0.665 \\
\hline
\end{tabular}

Table. 8 Comparison of pre harvest rice yield forecast models

\begin{tabular}{|c|c|c|c|c|c|c|c|}
\hline Model No. & $\begin{array}{l}\text { Forecasting } \\
\text { SMW no. }\end{array}$ & Year & $\begin{array}{l}\text { Observed } \\
\text { Yield }\end{array}$ & $\begin{array}{c}\text { Forecast } \\
\text { Yield }\end{array}$ & $\begin{array}{l}\text { Forecast } \\
\text { error }(\%)\end{array}$ & Adj. $\mathbf{R}^{2}$ & RMSE \\
\hline \multirow[t]{3}{*}{ Model-1 } & \multirow[t]{3}{*}{37} & 2010 & 2445 & 2179 & 10.85 & \multirow[t]{3}{*}{80.2} & \multirow[t]{3}{*}{378.53} \\
\hline & & 2011 & 2750 & 2193 & 20.25 & & \\
\hline & & 2012 & 2380 & 2159 & 9.27 & & \\
\hline \multirow[t]{3}{*}{ Model-2 } & \multirow[t]{3}{*}{37} & 2010 & 2445 & 1968 & 19.46 & \multirow[t]{3}{*}{66.5} & \multirow[t]{3}{*}{471.21} \\
\hline & & 2011 & 2750 & 2168 & 21.15 & & \\
\hline & & 2012 & 2380 & 2064 & 13.26 & & \\
\hline \multirow[t]{3}{*}{ Model-3 } & \multirow[t]{3}{*}{37} & 2010 & 2445 & 1968 & 19.46 & \multirow[t]{3}{*}{66.5} & \multirow[t]{3}{*}{471.21} \\
\hline & & 2011 & 2750 & 2168 & 21.15 & & \\
\hline & & 2012 & 2380 & 2064 & 13.26 & & \\
\hline \multirow[t]{3}{*}{ Model-4 } & \multirow[t]{3}{*}{36} & 2010 & 2445 & 2175 & 11.03 & \multirow[t]{3}{*}{69.1} & \multirow[t]{3}{*}{345.89} \\
\hline & & 2011 & 2750 & 2230 & 18.89 & & \\
\hline & & 2012 & 2380 & 2255 & 5.26 & & \\
\hline \multirow[t]{3}{*}{ Model-5 } & \multirow[t]{3}{*}{37} & 2010 & 2445 & 1968 & 19.46 & \multirow[t]{3}{*}{66.5} & \multirow[t]{3}{*}{471.21} \\
\hline & & 2011 & 2750 & 2168 & 21.15 & & \\
\hline & & 2012 & 2380 & 2064 & 13.26 & & \\
\hline
\end{tabular}

Fig.1 Trend of rice yield in Surat district 


\section{Rice Yield (Kg/ha)}

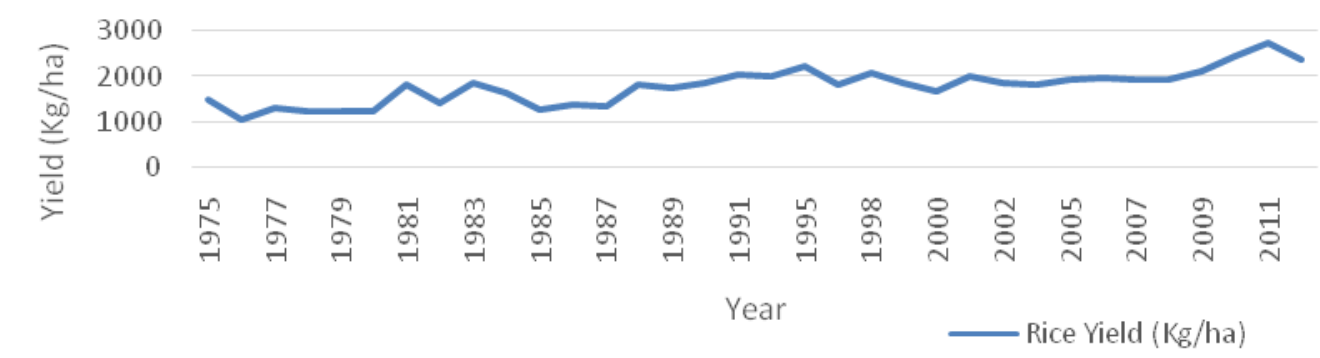

Fig.2 Graphical representation of observed yield and forecast yield

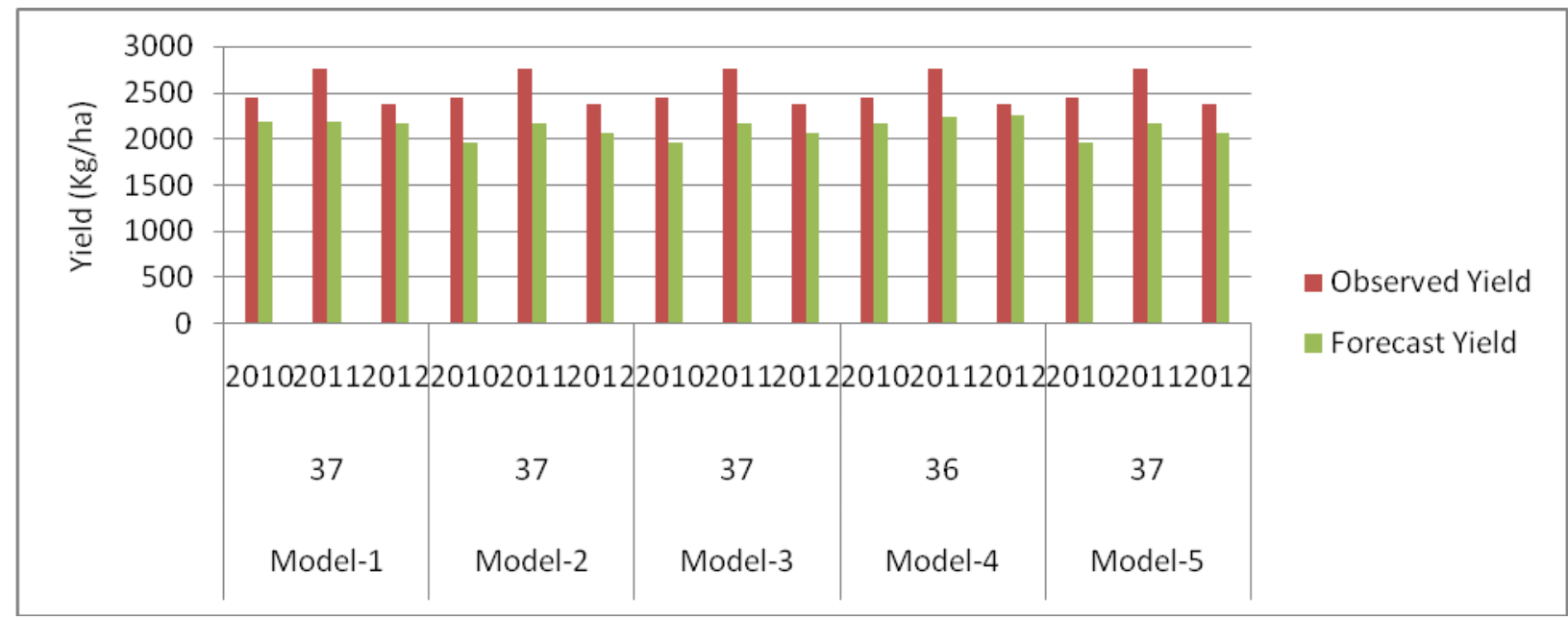

As discussed in method 3, the pre harvest rice yield forecast model 4equations are given in Table 6. The Table 6 observed that the values of adjusted $\mathrm{R}^{2}$ for different models were varied from 64.1 per cent (model $\mathrm{D}_{1}$ ) to 66.5 per cent (model $\mathrm{D}_{6}$ ). Based on highest value of adjusted $\mathrm{R}^{2}$ model $\mathrm{D}_{6}$ was selected as a best model among developed six models which found to be appropriate in the 37 SMW i.e. five weeks before the harvest of crop. The model showed 66.5 per cent variation accounted due to $d s_{1}$ and trend variable $T$.

As discussed in method 4, the pre harvest rice yield forecast model 5 equations are given in Table 7. The Table 7 observed that the values of adjusted $\mathrm{R}^{2}$ for different models were varied from 64.1 per cent (model $\mathrm{E}_{1}$ ) to 66.5 per cent (model $\mathrm{E}_{6}$ ). Based on highest value of adjusted $\mathrm{R}^{2}$ model $\mathrm{E}_{6}$ was selected as a best model among developed six models which found to be appropriate in the 37 SMW i.e. five weeks before the harvest of crop. The model showed 66.5 per cent variation accounted due to $d s_{1}$ and trend variable $T$.

\section{Comparison between models}

It was observed that different approaches of discriminant function analysis i.e. from model 2 to model 5 were more or less similar as coefficient of regression and values of adjusted $\mathrm{R}^{2}$. Comparison between models was carried out by using Adj. $\mathrm{R}^{2}$. The comparison of selected best fit models was done by forecast error and RMSE. The details of comparative study are given in Table 8 and the graphical representation is given in Figure 
2.

It observed from Table 8 that, the value of adjusted $\mathrm{R}^{2}$ varies from 66.5 to 80.2 and a value of RMSE varies from 345.89 to 471.21. The forecast error per cent varies from 9.27 to 20.25. The model 1 was selected as best fit model based on highest value $\mathrm{R}^{2}$ and comparatively low value of RMSE and forecast error per cent. Therefore pre-harvest forecasting was done using model 1 in the $37^{\text {th }} \mathrm{SMW}$ i.e. five weeks before harvest of the rice crop.

Based on the results discussed it was found that MLR techniques gave better forecast results than Discriminant function analysis for pre harvest forecasting of rice crop yield.

This study reveals that stepwise Multiple Linear Regression techniques (MLR) can be successfully used for pre-harvest crop yield forecasting. This model was most consistent and can be apply on zone or state level. The study also shows that use of de-trended yield data in model development gets most appropriate pre-harvest forecast models. The technique of discriminant function is found useful in classifying the crop year in to congenial, normal and adverse year with respect to crop yield. It can be concluded from the results that there is a wide scope for using alternative approaches to develop predictors that could be used in forecasting models for reliable and dependable forecast. Therefore, it is important to continue research on these aspects for various other crops also on a continuous basis. This methodology can be applicable in many crops viz. rice, pulses, oil seeds, sugarcane etc. to develop preharvest forecasting models and these forecasts have significant value in agricultural planning and policy making.

\section{References}

Agrawal, R. Jain, R.C. and Mehta, S.C., (2001). Yield forecast based on weather variables and agricultural inputs on agro-climatic zone basis. Ind. J. Agri. Sci., 71 (7), 487-490.

Agrawal, R.; Chandrahas and Kaustav A, (2011). Use of discriminant function analysis for forecasting crop yield. MAUSAM, 63(3): 455-458.

Agrawal, R.; Jain, R. C. and Jha, M. P. (1980). Modes for studying riceweather relationship. MAUSAM, 37(1): 67-70.

Anderson, T. W.; (1984). An Introduction to Applied Multivariate Statistical Analysis. John Wiley \& Sons, New York.

Dhekale, B. S; Sawant P. K. and Upadhye, T. P. (2014). Weather based pre-harvest forecasting of rice at Kolhapur (Maharashtra). Trends in Biosciences, 7(1): 39-41.

Draper, N.R. and Smith, H. (1981). Applied regression analysis, second edition, John Wiley and sons, New York

Fisher, R. A., (1924). The influence of rainfall on yield of wheat at Rothamsted. Philosophical Transaction of Royal Society of London, Series B, 213: 89142.

Food and Agriculture Organization, (2015). Rice market monitor, report 18(2): 2-6.

Garde, Y. A., Dhekale, B. S. and Singh, S., (2015). Different approaches on pre harvest forecasting of wheat yield. Journal of Applied and Natural Science, 7 (2): $839-843$.

Garde, Y. A.; Shukla, A. K.; Singh, S. (2012). Pre-harvest forecasting of rice yield using weather indices in Pantnagar. International Journal of Agricultural Statistical Science, 8(1): 233-241.

Gomez, K.A. and Gomez, A.A. (1984).Statistical Procedures in Agricultural Research. 2nd edition, New 
York, Chichester, etc.: Wiley Johnson; Richard, A. and Wichern, D. W. paperback, pp. 680

Hair; Joseph, F.; Anderson; Rolph, E.; Tatham; Ronald L. and Black, W. C.; (1995). Multivariate Data Analysis with Readings, Prentice Hall, Inc.New Jersey.

Hendricks, W. A. and Scholl, J. C. (1943). Technique in measuring joint relationship. The joint effect of temperature and precipitation on corn yield. N. C. Staff Agricultural Experimental Techniques Bulletin, 74.

Jain, R. C.; Agrawal, R. and Jha, M. P. (1980). Effect of climatic variables on (2006).Applied Multivariate Statistical Analysis, Pearson Education.

Kumar, N.; Pisal, R. R.; Shukla, S. P. and Pandey, K. K., (2016). Crop yield forecasting of paddy and sugarcane through modified Hendrick and Scholl technique for south Gujarat. MAUSAM, 67(2): 405-410.

Pisal, R.R., Kumar Neeraj and Shukla, S.P., (2017). Long term trend analysis of rainfall at heavy rainfall zone of South Gujarat, India. Ind. J. Soil Cons., 45(2): 168-175. rice yield and its forecast, MAUSAM, 31(3): 591-596.

\section{How to cite this article:}

Banakara K. B., Y. A. Garde, R. R. Pisal and Bhatt B. K. 2018. Pre-Harvest Forecasting of Rice Yield for Effective Crop Planning Decision in Surat District of South Gujarat. Int.J.Curr.Microbiol.App.Sci. 7(06): 3410-3422. doi: https://doi.org/10.20546/ijcmas.2018.706.400 